\title{
Analisis Kesalahan Mahasiswa dalam Menyelesaikan Soal Matematika Ditinjau dari Prosedur Newman
}

\author{
Daswarman \\ Universitas Bung Hatta \\ daswarman@bunghatta.ac.id
}

\begin{abstract}
A reason for students' low learning outcomes in Basic Mathematics 1 in PGSD FKIP Univer sitas Bung Hatta is found to be errors in answering the questions. This study aims to describe the errors and find factors that cause students errorly answer the questions in Basic Mathematics 1. This is a descriptive research using case study design with interview and test as data collection techniques. Errors analysis conducted with Newman Procedures shows that $4.89 \%$ of students experience Reading error, $8.22 \%$ of students experience Comprehension Error, $12.67 \%$ experience Transformation Error, $15.11 \%$ of students experience Process Skill Error, and $1.56 \%$ of students experience Encoding Error. Factors that cause errors include abhorrance of math, carelessness in solving problems, reluctance to ask questions during lecture, and the absence of motivation to learn.
\end{abstract}

Keywords : Errors, Basic Mathematics, Newman Procedures

This is an open access article distributed under the Creative Commons 4.0 Attribution License, which permits unrestricted use, distribution, and reproduction in any medium, provided the original work is properly cited. $\odot 2020$ by author and Universitas Negeri Padang.

\section{PENDAHULUAN}

Konsep Dasar Matematika I merupakan mata kuliah keahlian program studi Pendidikan Guru Sekolah Dasar (PGSD) FKIP Universitas Bung Hatta dengan capaian pembelajaran yaitu menguasai dan mengembangkan materi pembela jaran lima bidang studi utama di Sekolah Dasar. Mata kuliah ini merupakan mata kuliah yang harus diambil oleh mahasiswa semester I dengan bobot 3 sks. Mata kuliah ini merupakan pras yarat untuk mata kuliah semester berikutnya. Substansi kajian mata kuliah ini mencakup konsep-konsep dasar matematika yang berkaitan dengan ilmu bilangan, persamaan dan pertidak samaan, aritmatika, himpunan, dan logika mate matika serta penalaran dalam matematika. Maha siswa harus menguasai materi ini dengan baik melalui perkuliahan agar terciptanya pola pikir yang logis dan sistematis.

Senada dengan hal ini, Daswarman dan Alyusfitri (2017) menyatakan bahwa matema tika perlu diberikan sejak pendidikan di Seko lah Dasar (SD) agar siswa dibekali dengan kemampuan analitis, sistematis, kritis, dan krea tif, serta kemampuan bekerja sama. Karena itu perlu pembelajaran matematika dari jenjang SD sampai perguruan tinggi. Lebih lanjut Daswar man (2018), menegaskan, pembelajaran matema tika di perguruan tinggi diharapkan dapat me ningkatkan kemampuan matematika mahasiswa.
Matematika memiliki keterkaitan dengan ilmu-ilmu yang lainnya dan bermanfaat dalam kehidupan. Matematika tidak hanya untuk meng hitung saja, melainkan untuk pembuktian kebe naran ide dan pemecahan masalah secara siste matis dan logis. Kemampuan penyelesaian soal matematika dibutuhkan untuk mempelajari bi dang studi lain. Karena itulah matematika di anggap sebagai ilmu yang fundamental dan dipelajari dari pendidikan dasar, menengah sam pai perguruan tinggi (Rosmaiyadi, 2018). Pem belajaran matematika di Universitas dipengaruhi oleh lingkungan pergurun tinggi, maha siswa dan dosen serta penggunaan metode pembela jaran (Jana, 2018).

Pentingnya penguasaan matematika oleh mahasiswa sehingga mahasiswa diharapkan da pat menyelesaikan permasalahan matematika. Apabila mahasiswa tidak menguasai matematika maka akan dilakukan kesalahan-kesalahan da lam penyelesaian matematika. Terkait dengan kesalahan dalam penyelesaian soal ini, Jha (2012) menggunakan prosedur Newman untuk membuat analisis tentang kesalahan dalam menyelesaikan soal matematika. Terdapat lima kesalahan dalam penyelesaian matematika, yaitu 1) kesalahan membaca (Reading Errors), 2) kesalahan memahami masalah (Comprehension Errors), 3) kesalahan transformasi (Transfor mation Errors), 4) kesalahan perhitungan (Pro cess Skill Errors), 5) kesalahan menulis jawaban (Encoding Errors). 
Penyelesaian soal yang telah dibuat maha siswa perlu dianalisis. Analisis kesalahan ada lah suatu penyelidikan terhadap kesalahan atau ketidaksesuaian terhadap sesuatu hal yang be nar atau prosedur yang telah ditetapkan sebelum nya yang bersifat sistematis, konsisten, maupun insidental untuk mengetahui kekeliruan atau kesalahannya (Setiawan \& Hiltrimartin, 2018). Untuk meminimalisir kesalahan mahasiswa dalam mengerjakan soal matematika, maka dosen dalam mengajarkan matematika harus memahami bahwa terdapatnya perbedaan ke mampuan mahasiswa, serta ada sebagian maha siswa tidak menyenangi matematika (Heruman, 2007). Dosen dapat mengetahui kemampuan mahasiswa melalui jawaban soal matematika yang diberikan kepada mahasiswa. Dari jawaban soal tersebut dapat diketahui apakah mahasiswa benar atau salah dalam menjawab soal tersebut.

Mahasiswa dalam satu kelas berasal de ngan latar belakang yang berbeda. Secara psikis terdapat perbedaan motivasi di antara maha siswa. Ada mahasiswa dengan motivasi rendah maupun tinggi. Motivasi, minat, kemampuan se cara verbal dan perhitungan akan mempengaruhi keberhasilan pembelajaran matematika di kam pus (Jana, 2018).

Motivasi adalah dorongan dasar sebagai penggerak seseorang bertingkah laku (Uno, 2007). Mahasiswa dengan motivasi tinggi akan semangat belajar matematika, begitupun sebalik nya. Pada hakikatnya, motivasi merupakan do rongan baik secara internal maupun eksternal pada mahasiswa yang sedang belajar agar terja di perubahan tingkah laku yang meliputi bebe rapa indikator. Indikator tersebut di antaranya: 1) hasrat dan keinginan berhasil, 2) dorongan dan kebutuhan dalam belajar, 3) harapan dan cita-cita masa depan, 4) penghargaan dalam belajar, 5) kegiatan yang menarik dalam belajar, 6) lingkungan belajar yang kondusif sehingga memungkinkan seorang siswa dapat belajar dengan baik (Uno, 2007). Motivasi mahasiswa akan mempengaruhi hasil belajar mahasiswa yang bersangkutan.

Anita (2009) menjelaskan beberapa faktor yang berdampak terhadap hasil belajar: 1) faktor yang ada pada diri sendiri (intern) dan faktor yang ada pada luar diri (ekstern). Faktor dalam diri mahasiswa yaitu motivasi, minat, bakat, usaha, kecakapan, perhatian, kelemahan, kese hatan, dan kebiasaan mahasiswa. Salah satu hal yang perlu ditanamkan pada mahasiswa bahwa belajar merupakan kebutuhan dirinya. Faktor dari luar diri mahasiswa berupa lingkungan fisik dan nonfisik (suasana pembelajaran di kelas seperti suasana gembira, menyenangkan, ling kungan masyarakat, lingkungan keluarga, pro gram sekolah, guru dalam proses pembelajaran, dan teman di sekolah).

Berdasarkan pengamatan terhadap penger jaan soal matematika yang dilakukan mahasis wa, maka ditemukan beberapa kesalahan dalam menyelesaikan soal matematika. Kesalahan seba gian besar mahasiswa dalam menyelesaikan soal yaitu kesalahan dalam perhitungan dan menggu nakan rumus yang sesuai dengan soal. Kesa lahan-kesalahan ini akan berdampak terhadap hasil belajar mahasiswa. Oleh karena itu, kesa lahan-kesalahan tersebut perlu diketahui dosen agar dapat membantu mahasiswa mengetahui dimana letak kesalahannya dan mengetahui penyebabnya. Diharapkan dosen dapat mengam bil tindakan yang tepat untuk mengatasi kesa lahan ini agar hasil belajar mahasiswa bisa meningkat. Karena itu, pada penelitian ini dikaji tentang kesalahan-kesalahan apa saja yang dila kukan mahasiswa ketika dihadapkan dengan soal matematika dan faktor apa saja yang menjadi penyebab kesalahan tersebut. Faktor kesalahan baik intern maupun ekstern seperti motivasi dan lingkungan mahasiswa.

Beberapa penelitian mengenai analisis ke salahan menggunakan prosedur Newman telah dilakukan dengan subjek penelitian mahasiswa di perguruan tinggi, siswa di tingkat Sekolah Menengah Atas (SMA) maupun bagi Siswa Sekolah Dasar (SD). Amalia (2017) fokus peneli tiannya pada kesalahan mahasiwa menyelesai kan soal cerita ditinjau dari gaya kognitif. Hasil penelitiannya terdapat kesalahan mahasiswa tipe Field Independent (FI) dan tipe Field Dependent $(F D)$. Kesalahan kedua tipe ini adalah kesalahan memahami masalah, keterampilan proses dan penarikan kesimpulan. Kesalahan transformasi hanya dilakukan oleh mahasiswa tipe FD. Se dangkan Suyitno \& Suyitno (2015) menggu nakan prosedur Newman untuk menentukan kesalahan mahasiswa sehingga dosen dapat memberikan learning therapy. Learning therapy ini membuat mahasiswa benar dan akurat menyelesaikan soal tertulis.

Penelitian menggunakan prosedur New man untuk siswa SMA telah dilakukan Jamal (2018) terhadap empat orang siswa kelas X SMA Negeri 3 Meulaboh. Kajian utama peneli tiannya mengenai pertidaksamaan kuadrat. Hasil penelitiannnya kesalahan membaca dan mema 
hami tidak dilakukan keempat subjek. Kesa lahan transformasi dilakukan satu orang subjek, dua orang subjek melakukan kesalahan keteram pilan proses, dan satu orang subjek melakukan kesalahan penulisan jawaban. Penelitian pada siswa SMA juga dilakukan Rahmawati dan Permata (2018). Hasil penelitiannya menunjuk kan bahwa kesalahan terbesar dari prosedur Newman bagi siswa SMAN I Wonosari adalah kesalahan pemahaman $81,67 \%$ pada materi program linier.

Penggunaan prosedur Newman ini untuk menganalisis kesalahan siswa SD diantaranya diteliti oleh Singh, dkk (2010) pada siswa kelas empat SD di Malaysia. Hasil penelitiannya seca ra kolektif (baik perkotaan maupun perdesaan), kesalahan siswa terkait bahasa dan sisanya 68\% terkait dengan konten. Sebelumnya, Prakitipong dan Nakamura (2006) menganalisis kinerja mate matika siswa kelas lima SD di Thailand. Seba gian besar kesalahan siswa terjadi pada tingkat pemahaman untuk pertanyaan terstruktur. Se mentara kesalahan untuk pertanyaan pilihan ganda terjadi di tingkat transformasi. Kesalahan berkinerja baik tidak terjadi pada tingkat memba ca, tetapi kesalahan berkinerja buruk sebagian besar terjadi pada tingkat pemahaman.

Berdasarkan penelitian-penelitian yang telah dilakukan oleh peneliti terdahulu, maka dilakukan penelitian untuk meneliti kesalahan mahasiswa menggunakan prosedur Newman untuk mahasiswa program Studi Pendidikan Guru Sekolah Dasar (PGSD). Mahasiswa PGSD ini merupakan mahasiswa yang dididik untuk menjadi guru SD. Penelitian ini penting dilaku kan agar diketahui kesalahan-kesalahan mahasis wa dalam mengerjakan soal matematika. Berda sarkan kesalahan-kesalahan tersebut, Dosen sebaiknya memberikan catatan pada lembar ujian mahasiswa tentang kesalahan yang telah dibuat mahasiswa agar mahasiswa menyadari letak kesalahannya berdasarkan tipe kesalahan yang telah diperbuat.

\section{METODE PENELITIAN}

Penelitian dilaksanakan di Program Studi (Prodi) PGSD Fakultas Keguruan dan Ilmu Pendidikan (FKIP) Universitas Bung Hatta. Penelitian ini dilakukan pada semester ganjil tahun akademik 2019/2020. Objek penelitian mahasiswa semester 1 sebanyak 45 orang.

Penelitian ini menggunakan metode pene litian deskriptif dengan desain studi kasus. Lufri
(2007) menyatakan bahwa penelitian deskriptif merupakan penelitian yang mendeskripsikan suatu keadaan berupa gejala, keadaan, peristiwa atau kejadian yang sedang atau sudah terjadi. Lebih lanjut Lufri (2007) menegaskan bahwa penelitian kasus merupakan studi mendalam mengenai individu, kelompok, atau lembaga. Penelitian deskriptif terfokus pada masalahmasalah aktual yang sedang atau telah terjadi dan diungkapkan apa adanya. Penelitian ini mendeskripsikan kesalahan mahasiswa dalam menyelesaiakan soal matematika dan penyebab kesalahan yang dilakukan. Contohnya dalam pemecahan masalah bilangan biner. Terdapat beberapa kesalahan mahasiswa diantaranya kesalahan dalam menentukan nilai bilangan berpangkat dan kesalahan dalam menjumlahkan bilangan.

Ada dua pengumpulan data yang diguna kan pada penelitian ini yaitu wawancara dan tes. Wawancara dengan mahasiswa dan tes yang terdiri dari 5 butir soal Matematika Dasar I. Wawancara dilakukan untuk mengetahui faktor apa saja yang menyebabkan kesalahan mahasis wa ketika menjawab soal. Sedangkan tes diguna kan untuk mengetahui kesalahan yang dilakukan pada penyelesaian soal.

Perhitungan persentase kesalahan tiap bu tir soal menggunakan rumus yang dimodifikasi dari Trianto (2009).

$$
\mathrm{F}=\frac{\mathrm{A}}{\mathrm{B}} \times 100 \%
$$

Keterangan :

$\mathrm{F}=$ Persentase kesalahan

$\mathrm{A}=$ Proposi mahasiswa yang jawabannya salah

$\mathrm{B}=$ Jumlah mahasiswa

\section{HASIL DAN PEMBAHASAN}

Hasil tes yang dikerjakan oleh mahasiswa berkaitan dengan materi bilangan biner, persa maan dan pertidaksamaan linier, persamaan dan pertidaksamaan kuadrat semuanya diperiksa dan kemudian ditemukan kesalahan-kesalahan dalam menjawab soal tersebut. Terdapat kesalahan yang berbeda diantara mahasiswa. Jika terdapat kesalahan yang sama maka satu saja yang men jadi pembahasan. Rekapitulasi kesalahan maha siswa dapat dilihat pada Tabel 1.

Tipe kesalahan yang dilakukan mahasis wa berdasarkan Tabel 1 adalah:

1) Tipe Kesalahan Membaca (Reading $\mathrm{Er}$ rors). Terdapat 5 butir soal yang dikerjakan 
oleh 45 mahasiswa dengan $4,89 \%$ kesa lahan membaca.

2) Tipe Kesalahan Memahami masalah (Com prehension Errors). Terdapat 5 butir soal yang dikerjakan oleh 45 mahasiswa dengan $8,22 \%$ kesalahan membaca.

3) Tipe Kesalahan Transformasi (Transforma tion Errors). Terdapat 5 butir soal yang di kerjakan oleh 45 mahasiswa dengan 12,67\% kesalahan transformasi.

4) Tipe Kesalahan Perhitungan (Process Skill Errors). Terdapat 5 butir soal yang dikerja kan oleh 45 mahasiswa dengan 15,11\% kesalahan perhitungan.

5) Tipe Kesalahan Menulis Jawaban (En coding Errors). Terdapat 5 butir soal yang dikerjakan oleh 45 mahasiswa dengan $1,56 \%$ kesalahan menulis jawaban.

Tabel 1.Kesalahan dalam Penyelesaian Soal

\begin{tabular}{|c|c|c|c|c|c|}
\hline \multirow{2}{*}{$\begin{array}{c}\text { Nomor } \\
\text { Soal }\end{array}$} & \multicolumn{5}{|c|}{ Tipe Kesalahan } \\
\hline & 1 & 2 & 3 & 4 & 5 \\
\hline $1 \mathrm{a}$ & 2,22 & & & 31,11 & \\
\hline $1 \mathrm{~b}$ & 17,78 & 48,89 & & 4,44 & \\
\hline $1 \mathrm{c}$ & 15,56 & 8,89 & 24,44 & $13, .33$ & \\
\hline $1 \mathrm{~d}$ & & & & 26,67 & \\
\hline $2 \mathrm{a}$ & & 2,22 & 13,33 & 11,11 & \\
\hline $2 b$ & & & 6,67 & 31,11 & \\
\hline $3 a$ & & 4,44 & 28,89 & 11,11 & 4,44 \\
\hline $3 b$ & & 13,33 & 13,33 & 2,22 & \\
\hline 4 & 6,67 & 2,22 & 13,33 & 15,56 & 6,67 \\
\hline 5 & 6,67 & 2,22 & 26,67 & 4,44 & 4,44 \\
\hline $\begin{array}{l}\text { Rata- } \\
\text { rata }\end{array}$ & 4,89 & 8,22 & 12,67 & 15,11 & 1,56 \\
\hline
\end{tabular}

Keterangan kesalahan :

1 : Kesalahan Membaca (Reading Errors)

2 : Kesalahan Memahami masalah (Comprehension Errors)

3 : Kesalahan Transformasi (Transformation Errors)

4 : Kesalahan Perhitungan (Process Skill Errors)

5 : Kesalahan Menulis Jawaban (Encoding Errors)

Berdasarkan pengolahan data yang dida pat pada Tabel 1 di atas diketahui bahwa tipe kesalahan yang sering dilakukan mahasiswa da lam menyelesaikan soal yaitu kesalahan perhi tungan, kesalahan transformasi, kesalahan mema hami soal, kesalahan membaca dan kesalahan menulis jawaban. Penjelasan lebih lanjut dapat dilihat pada Gambar 1. Kesalahan perhitungan yang terdapat pada semua butir soal. Kesalahan transformasi tidak terdapat pada butir soal no mor 1 kecuali 1c. Kesalahan memahami tidak terdapat pada butir soal 1a, 1d dan 2b. Kesa lahan membaca terdapat pada butri soal nomor 1a, 2 dan 3. Sedangkan kesalahan dalam menulis jawaban terdapat pada soal nomor 1, 2 dan $3 b$.

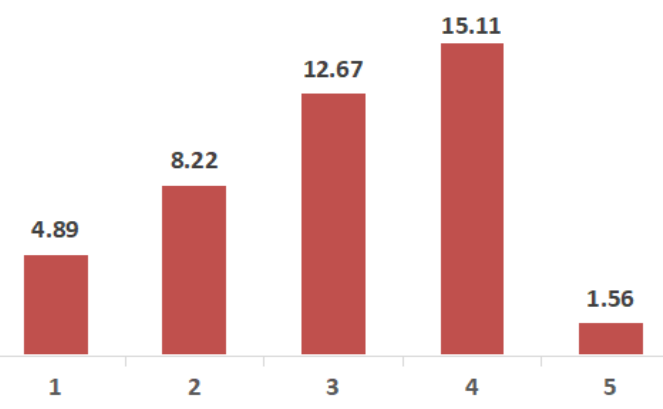

Gambar 1. Persentase Tipe Kesalahan

Kesalahan perhitungan dilakukan maha siswa disebabkan kesalahan dalam menjumlah, mengurangi, mengali dan membagi. Penyebab kesalahan ini karena kurang teliti membaca soal dan lemahnya pemahaman mahasiswa terhadap perhitungan itu sendiri (Malihatuddarojah \& Prahmana, 2019). Kesalahan membaca akibat kurang telitinya mahasiswa memperhatikan soal. Kesalahan pemahaman terkait dengan konsep yang tidak dikuasai mahasiswa. Kesalahan trans formasi berhubungan dengan pengetahuan ten tang penentuan penggunaan rumus yang tepat dalam penyelesaian soal. Sedangkan kesalahan menulis jawaban akibat kecerobohan dalam penulisan jawaban akhir dari soal. Berikut ini ditampilkan tabel rata-rata kesalahan dalam pengerjaan soal matematika.

Tabel 2. Rata-Rata Kesalahan dalam Pengerjaan Soal Matematika.

\begin{tabular}{|c|c|}
\hline Nomor Soal & Rata-Rata Kesalahan \\
\hline $1 \mathrm{a}$ & 6,67 \\
\hline $1 \mathrm{~b}$ & 14,22 \\
\hline $1 \mathrm{c}$ & 12,44 \\
\hline $1 \mathrm{~d}$ & 5,33 \\
\hline $2 \mathrm{a}$ & 5,33 \\
\hline $2 \mathrm{~b}$ & 7,56 \\
\hline $3 \mathrm{a}$ & 9,78 \\
\hline $3 \mathrm{~b}$ & 5,78 \\
\hline 4 & 8,89 \\
\hline 5 & 8,89 \\
\hline
\end{tabular}

Rata-rata kesalahan tertinggi terdapat pa da soal $1 \mathrm{~b}$ sebesar $14,22 \%$. Kesalahan ini terda pat pada soal mengenai bilangan biner. Kesa lahan terbesar terjadi pada kesalahan memahami masalah sebesar 48,89\% seperti terlihat pada Tabel 1. Hal ini terjadi karena kurangnya pema haman mahasiswa terhadap konsep bilangan biner. Rata-rata kesalahan terendah terdapat pada soal nomor 1d dan 2a sebesar 5,33\%. Soal 1d tentang mengubah bilangan basis sepuluh 
menjadi bilangan basis dua. Sedangkan soal 2a adalah persamaan linier satu variabel.

Berdasarkan kesalahan-kesalahan mahasis wa mengerjakan soal, diperoleh beberapa kesa lahan yang dapat dilihat pada beberapa contoh di bawah ini. Contoh kesalahan membaca dapat dilihat pada Gambar 2.

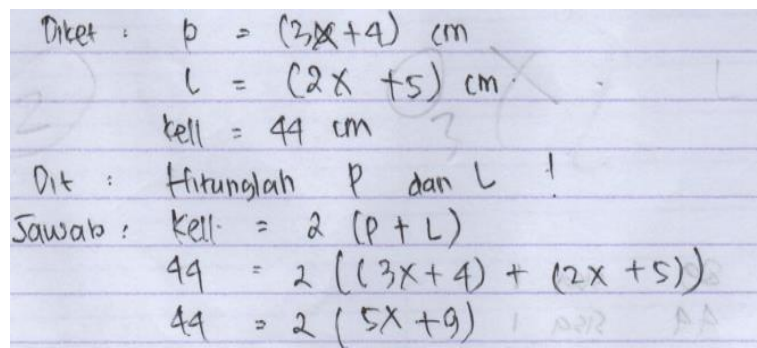

\section{Gambar 2. Kesalahan Membaca}

Mahasiswa menulis diketahui $\mathrm{L}=(2 \mathrm{x}+5)$ sedang kan di soal lebar adalah $(2 x+3)$. Mahasiswa salah membaca soal sehingga salah menulis soal akibatnya jawaban mahasiswa tidak sesuai dengan soal yang seharusnya. Mahasiswa perlu teliti membaca soal sehingga kesalahan ini tidak terjadi.

Contoh kesalahan memahami masalah seperti pada Gambar 3 .

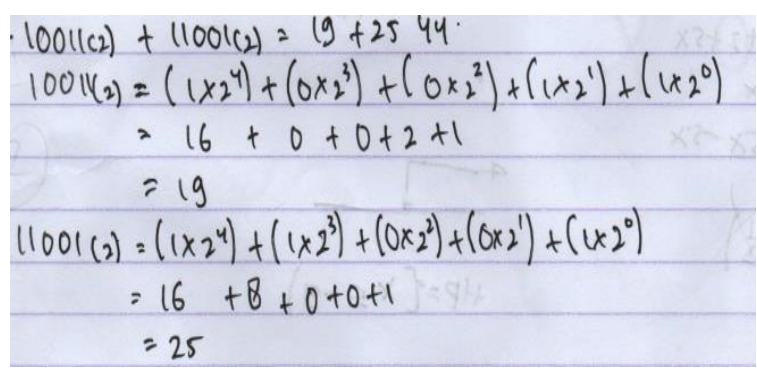

Gambar 3. Kesalahan Memahami Masalah

Mahasiswa tidak memahami soal tentang pen jumlahan bilangan biner basis 2. Pengerjaan soal mahasiswa adalah mengubah basis 2 ke basis 10 dan menjumlahkan kedua bilangan yang telah diubah ke basis 10 sehingga menghasilkan pen jumlahan dalam basis 10. Penjumlahan yang seharusnya dilakukan mahasiswa adalah penjum lahan bilangan biner tanpa harus mengubah ke basis sepuluh. Mahasiswa tidak memahami ten tang penjumlahan bilangan biner sehingga meng gunakan bilangan basis sepuluh untuk menyele saikan penjumlahan bilangan biner. Kesalahan memahami tentang penjumlahan bilangan biner disebabkan kurangnya pemahaman konsep bilangan biner dan tidak bisa menuliskan apa yang ditanya pada soal tersebut.

Contoh kesalahan transformasi seperti pada Gambar 4.

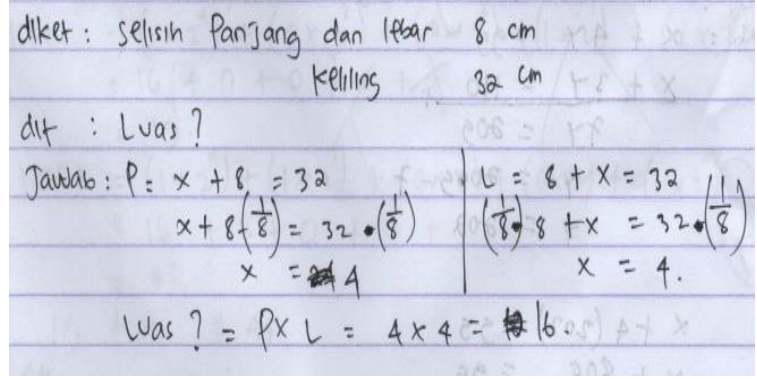

Gambar 4. Kesalahan Transformasi

Soal pada penyelesaian di atas adalah sebagai berikut. Selisih panjang dan lebar suatu persegi panjang PQRS adalah $8 \mathrm{~cm}$, sedangkan keliling daerahnya $32 \mathrm{~cm}$. Hitunglah luas daerah persegi panjang PQRS tersebut. Kesalahan mahasiswa dalam penentuan selisih panjang dan lebar per segi panjang mengakibatkan kesalahan dalam penentuan luas persegi panjang. Mahasiswa te lah salah sebelumnya tentang panjang dan lebar persegi panjang. Kesalahan ini terjadi karena mahasiswa salah dalam menentukan rumus un tuk selisih panjang dan lebar sesuai dengan soal yang diberikan.

Kesalahan pehitungan dapat dilihat pada Gambar 5.

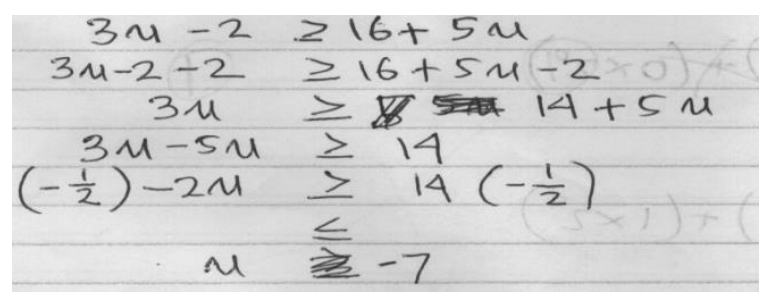

Gambar 5. Kesalahan Perhitungan

Pada baris kedua dan ketiga terlihat kesalahan mahasiswa dalam perhitungan. Kesalahan dalam menghitung yaitu $-2-2=0$. Mahasiswa ingin menghilangkan -2 pada ruas sebelah kiri, tetapi mahasiswa salah dalam menghilangkan -2 pada baris kedua. Seharusnya pada barus kedua di tambah dengan 2 baik ruas kiri mapun ruas ka nan. Mahasiswa telah memahami tentang kon sep pertidaksamaan akan bernilai sama dengan pertidaksamaan sebelumnya jika kedua ruas di kurangi dengan bilangan yang sama. Tetapi aki bat kesalahan dengan mengurangi -2 di kedua ruas justru tidak menyelesaikan pertidaksamaan tersebut. Akibatnya tidak dapat ditentukan bera pa nilai $\mathrm{x}$ dari pertidaksamaan.

Kesalahan menulis jawaban terlihat pada Gambar 6. Mahasiswa sudah benar dalam penye lesaian pembagian untuk mengubah bilangan basis 10 menjadi bilangan basis 2. Mahasiswa 
telah benar menghitung bilangan yang dibagi 2 berikut dengan sisanya.

$179(10)=\quad$ (2)
$179: 2=89 \quad$ sija 1
$89: 2=44$ sisa 1
$44: 2=22$ sisa 0
$22: 2=11$ sisa 0
$11: 2=5 \quad$ sisa 1
$5: 2=2 \quad$ sisa 1
$2: 2=1 \quad$ sisa $0+1=1$
Jadi $1110011 \quad$ (2)

Gambar 6. Kesalahan Menulis Jawaban

Permasalahannya terdapat kesalahan dalam me nulis jawaban. Jawaban yang seharusnya adalah $10110011_{(2)}$, sedangkan mahasiwa menulis $1110011_{(2)}$.

\section{Faktor Penyebab Kesalahan}

Untuk mengetahui hal-hal yang menjadi penyebab kesalahan mahasiswa dalam menyele saikan soal, maka dilakukan wawancara dengan mahasiswa sebagai responden. Berikut ini rekapi tulasi wawancara penulis mengenai kesalahan mahasiswa dalam menyelesaikan soal.

1. Kesulitan memahami matematika disebab kan tidak suka dengan matematika. Hal ini tentu tidak baik karena mahasiswa tidak hanya belajar dengan matematika, tetapi nanti setelah tamat dan menjadi guru, maka mahasiswa tersebut justru akan mengajar kan matematika ke siswanya. Kendala ini bisa diatasi dengan mempersiapkan kemam puan mengajar mahasiswa melalui mata kuliah pembelajaran matematika. Pada Pro di PGSD, mahasiswa diwajibkan mengam bil mata kuliah Pembelajaran Matema tika I dan Pembelajaran Matematika II. Melalui mata kuliah pembelajaran matematika I dan pembelajaran matematika II ini mahasiswa dibimbing dosen untuk memahami konsep matematika dan praktik mengajar menggu nakan metode pembelajaran. Penggunaan metode akan mempengaruhi hasil belajar, (Amelya, dkk. 2018). Salah satu metode yang bisa digunakan adalah metode pem belajaran kooperatif. Berdasarkan peneli tian Putri \& Daswarman (2017) dan Tullah dan Daswarman (2017) terdapat pening katan hasil belajar dengan menggunakan pembelajaran kooperatif dibandingkan pem belajaran konvensional.

2. Tidak teliti dalam menyelesaikan perhi tungan. Hal ini disebabkan dengan kecero bohan dan keinginan cepat menyelesaikan soal tanpa memeriksa kembali apakah jawaban tersebut sudah benar atau salah. Mahasiswa perlu memaksimalkan waktu ujian sehingga dengan waktu yang tersedia diharapkan mahasiswa bisa menjawab soal dengan baik dan memeriksa kembali jawa bannya jika masih ada waktu.

3. Tidak bisa menjawab soal karena tidak mengerti. Dalam perkuliahan tidak mau bertanya dan ada rasa malu untuk bertanya. Dosen harus menciptakan suasana kondusif sehingga pembelajaran berjalan dengan baik dan terjadi interaksi antara dosen dan mahasiswa. Mahasiswa seharusnya berta nya jika belum mengerti tentang materi kuliah sehingga materi kuliah bisa dipa hami dengan baik.

4. Kurangnya motivasi dalam belajar matema tika. Oleh karena itu, diperlukan peran dosen dalam memacu motivasi mahasiwa dalam belajar matematika.

Rosmaiyadi (2018) dan Jana (2019) mene mukan bahwa kesalahan mahasiswa dalam menyelesaikan matematika disebabkan oleh kesalahan dalam perhitungan, kesalahan penggu naan rumus, kesalahan konsep dan kesalahan memahami soal. Kurangnya pemahaman kon sep mahasiswa disebabkan motivasi, metode pembelajaran, dosen, sarana prasarana dan ling kungan kampus (Muhammad \& Karso, 2018). Beberapa penyebab kesalahan ini perlu dikaji dan disampaikan kepada mahasiswa agar maha siswa tidak melakukan kesalahan dalam penger jaan soal matematika. Berkurangnya kesalahan yang dilakukan dalam pengerjaan soal akan berdampak terhadap peningkatan hasil belajar.

\section{KESIMPULAN}

Kesalahan-kesalahan mahasiswa menyele saikan soal Matematika Dasar I adalah : 1) kesa lahan membaca (Reading Errors) sebanyak 4,89\% dari 45 orang mahasiswa, 2) Kesalahan memahami masalah (Comprehension Errors) sebanyak 8,22\%, 3) kesalahan transformasi (Transformation Errors) sebanyak 12,67\% a, 4) kesalahan perhitungan (Process Skill Errors) sebanyak $15,11 \%, 5)$ kesalahan menulis Jawa ban (Encoding Errors) sebanyak 1,56\%. 
Faktor penyebab kesalahan menyelesai kan soal Matematika Dasar I adalah : 1) tidak menyukai matematika, 2) kurangnya motivasi mahasiswa, 3) kecerobohan dalam menjawab soal, 4) rasa takut bertanya saat perkuliahan. Ada mahasiswa yang mengikuti perkuliahan dengan motivasi rendah seperti terlambat hadir atau tidak mengerjakan tugas yang diberikan dosen. Dosen harus mengubah pola pikir maha siswa akan pentingnya belajar dalam perku liahan. Dosen juga harus membangkitkan moti vasi mahasiswa untuk belajar sehingga hasil belajar bisa meningkat. Untuk peneliti selan jutnya bisa melanjutkan penelitian dengan meng analisis kesalahan matematika mahasiswa PGSD untuk mata kuliah Matematika Dasar II.

\section{DAFTAR PUSTAKA}

Amalia, S. R. (2017). Analisis Kesalahan Berda sarkan Prosedur Newman dalam Menyele saikan Soal Cerita Ditinjau dari Gaya Kognitif Mahasiswa. AKSIOMA: Jurnal Matematika dan Pendidikan Matematika, 8(1), 17-30.

Amelya, V., Nurharmi, N., \& Daswarman, D. (2018). Pengaruh Model Pembelajaran Kooperatif Tipe Take And Give Terhadap Hasil Belajar Siswa Pada Tema Keperluan Sehari-Hari pada Siswa Kelas III di SD Negeri 20 Kurao Pagang Kota Padang. Abstract of Undergraduate, Faculty of Education, Bung Hatta University, 8(3).

Anitah W, Sri. (2009). Materi Pokok Strategi Pembelajaran SD. Jakarta: Universitas Ter buka.

Daswarman. (2018). Pengaruh Metode Eksposi tori Terhadap Pemahaman Konsep Mate matika Mahasiswa PGSD. Jurnal Cerdas Proklamator, 2(1).

Daswarman, D. \& Alyusfitri, R. (2017). Pengem bangan Modul Luas dan Keliling Bangun Datar yang Valid dengan Pendekatan Kon tekstual Berbasis Keunggulan Lokal di Se kolah Dasar. Lemma, 3(2).

Heruman. (2007). Model Pembelajaran Matema tika di Sekolah Dasar, Bandung: PT Rosda Karya.

Jamal, F. (2018). Analisis Kesalahan dalam Me nyelesaikan Soal Cerita Pertidaksamaan Kuadrat Berdasarkan Prosedur Newman. MAJU: Jurnal Ilmiah Pendidikan Matema tika, 5(2).
Jana, Padrul (2018). Analisis Kesalahan Maha siswa dalam Menyelesiakn Soal Matemati ka pada Pokok Bahasan Vektor. Jurnal Penelitian dan Pendidikan Matematika, 2(2), 1-7.

Jha, S. K. (2012). Mathematics performance of primary school students in assam (india): an analysis using newman procedure. In ternational Journal of Computer Applica tions in Engineering Sciences, 2(1), 17-21.

Lufri. (2007). Kiat Memahami dan Melakukan Penelitian. Padang: UNP Press.

Malihatuddarojah, D., \& Prahmana, R. C. I. (2019). Analisis kesalahan siswa dalam menyelesaikan permasalahan operasi ben tuk aljabar. Jurnal Pendidikan Matematika, 13(1), 1-8.

Muhammad, G. M., \& Karso. P (2018). Pene rapan Model Guided Discovery Learning Untuk Meningkatkan Pemahaman Konsep Matematis Mahasiswa. Jurnal Eksakta Pen didikan, 2(1), 108-115.

Prakitipong, N., \& Nakamura, S. (2006). Analy sis of mathematics performance of grade five students in Thailand using Newman procedure. Journal of International Coope ration in Education, 9(1), 111-122.

Putri, R. W., \& Daswarman, D. (2017). Pene rapan Model Pembelajaran Kooperatif Tipe Numbered Head Together pada Hasil Bela jar Matematika Siswa Kelas V SDN 15 Sungai Geringging. Abstract of Undergra duate, Faculty of Education, Bung Hatta University, 8(1).

Rahmawati, D., \& Permata, L. D. (2018). Anali sis Kesalahan Siswa Dalam Menyelesaikan Soal Cerita Program Linear Dengan Prose dur Newman. Jurnal Pembelajaran Mate matika, 5(2).

Rosmaiyadi, R. (2018). Analisis kesalahan penyelesaian soal aljabar pada mahasis wa program studi pendidikan matematika Stkip Singkawang. Jurnal Pendidikan Mate matika, 12 (1), 59-70.

Setiawan, Y., Hapizah, H., \& Hiltrimartin, C. (2018). Kesalahan siswa dalam menyele saikan soal olimpiade SMP konten alja bar. Jurnal Riset Pendidikan Matema tika, 5(2), 233-243.

Singh, P., Rahman, A. A., \& Hoon, T. S. (2010). The newman procedure for analyzing pri mary four pupils errors on written mathe matical tasks: A Malaysian perspective. 
Procedia-Social and Behavioral Sciences, 8, 264-271.

Suyitno, A., \& Suyitno, H. (2015). Learning therapy for students in mathematics com munication correctly based-on application of Newman procedure (a case of Indone sian student). International Journal of Education and Research, 3(1), 529-538.

Uno, Hamzah B. (2007). Teori Motivasi dan Pengukurannya Analisis di Bidang Pendi dikan. Jakarta: Bumi Aksara.
Trianto. (2009). Mendesain Model Pembela jaran Inovatif-Progresif. Jakarta: Kencana Prenada Media Group.

Tullah, R. H., \& Daswarman, D. (2017). Penga ruh Penerapan Model Pembelajaran Koope ratif Tipe Take And Give Terhadap Hasil Belajar IPA Siswa Kelas V di SD Negeri 03 Batipuh Kabupaten Tanah Datar. $A b$ stract of Undergraduate, Faculty of Educa tion, Bung Hatta University, 8(1). 